\title{
OPEN Piezoelectric energy harvester with double cantilever beam undergoing coupled bending-torsion vibrations by width-splitting method
}

\author{
Jiawen Song ${ }^{1}$, Guihong Sun ${ }^{2}$, Xin Zeng ${ }^{3}$, Xiangwen $\mathrm{Li}^{1}$, Quan Bai ${ }^{1}$ \& Xuejun Zheng ${ }^{1 凶}$
}

We propose piezoelectric energy harvester $(\mathrm{PEH})$ with double-cantilever-beam (DCB) undergoing coupled bending-torsion vibrations by combining width-splitting method and asymmetric mass, in order that more ambient energy could be harvested from environmental vibration with multiplefrequency excitation. The geometrical dimensions are optimized for PEHDCB, when the maximum of output peak voltages $U_{p-\max }$ and resonance frequency difference $\left(\Delta f_{0}\right)$ between the first and second modes are chosen as optimization objectives based on orthogonal test method. The energy harvesting efficiency is evaluated by the proportion of half-power bandwidth and quality factor, and the experimental and simulation results are compared to verify reliability. The $U_{p-\max 1}$ and $P_{p-\max 1}$ are increased $25.2 \%$ and $\mathbf{5 7 . 3 \%}$ for PEHDCB under the multi-frequency excitation, when the split-width method is applied into $\mathrm{PEH}$ with single-cantilever-beam (SCB) undergoing coupled bending-torsion vibrations. The deviations of $U_{\mathrm{p}-\max 1}$ and $f_{0}$ are at the ranges of 4.9-14.2\% and $2.2-2.5 \%$ for PEHDCB under the different mass ratios, and the measurement reliability is acceptable considering incomplete clamping, damping and inevitable assembly effects. The energy harvesting efficiency of PEHDCB presented is much higher than that of the conventional PEHSCB from environmental vibration with multiple-frequency excitation.

In recent years, harvesting ambient energy using piezoelectric effect is considered to be an important energy conversion technology applicable to future industries along with photovoltaics ${ }^{1}$, thermoelectrics ${ }^{2}$, radio frequencies ${ }^{3}$, and triboelectric technology ${ }^{4}$. Vibration-based piezoelectric energy harvester is a potential candidate to replace existing power sources such as the batteries which have a limited energy storage capacity and lifetime for some applications ${ }^{5}$. Based on Taguchi orthogonal method, the variation in the excitation frequency, the thickness of piezoelectric layers and the acceleration of the bimorph piezoelectric energy harvester (PEH) were optimized by maximum output peak voltage $\left(\mathrm{U}_{\mathrm{p}-\max }\right)$ and signal-to-noise ratio as the optimization objectives ${ }^{6}$, and the ultimate goal is that one could obtain the $U_{\mathrm{p}-\max }$ with lesser trials ${ }^{7}$. Most of PEHs with the different beam shapes, such as the rectangles ${ }^{8-11}$ and triangles ${ }^{12,13}$ have been focused on the energy harvesting characteristics from bending vibration, and the main problem is the significant dropping of output power when the excitation frequency slightly away from the natural frequency of the harvesters. The durability of PEH is importance to sustainable power wireless sensors, and some researchers have focused on the fatigue analysis for PEH under different excitation cycles ${ }^{14}$ and levels of base excitation ${ }^{15}$.

$\mathrm{PEH}$ can effectively harvest electric power from torsional vibration by attaching a simple cantilever beam structure on the top surface of a rotating shaft generate ${ }^{16}$. A unimorph cantilever beam undergoing bendingtorsion vibrations has been proposed by asymmetry increasing under a transverse harmonic base excitation to narrow the resonance frequency difference $\left(\Delta f_{0}\right)$ between first and second modes, therefore it allows the harvesting of electrical power from multiple-frequency excitation ${ }^{17}$. The novel asymmetric vortex-induced piezoelectric

\footnotetext{
${ }^{1}$ School of Mechanical Engineering, Engineering Research Center of Complex Tracks Processing Technology and Equipment of MoE, Key Laboratory of Welding Robot and Application Technology of Hunan Province, Xiangtan University, Xiangtan 411105, People's Republic of China. ${ }^{2}$ Key Xiangtan Hongda Vacuum Technology Co., Ltd., Xiangtan 411104, People's Republic of China. ${ }^{3}$ Wasion Electric Co., Ltd., Xiangtan University, Xiangtan 411199, People's Republic of China. ${ }^{\circledR}$ email: zhengxuejun@xtu.edu.cn
} 


\begin{tabular}{|l|l|l|l|}
\hline Brass & 100 & Poisson's ratio & 0.3 \\
\hline Young's modulus $(\mathrm{GPa})$ & 9000 & Yield strength $(\mathrm{MPa})$ & 200 \\
\hline Density $\left(\mathrm{kg} / \mathrm{m}^{3}\right)$ & 7750 & Yield strength $(\mathrm{MPa})$ & 60 \\
\hline PZT-53 & 65 & Mechanical damping ratio $\zeta_{\mathrm{m}}$ & 0.007 \\
\hline Density $\left(\mathrm{kg} / \mathrm{m}^{3}\right)$ & & $s_{11}^{\mathrm{E}}=15 s_{33}^{\mathrm{D}}=8.8 s_{55}^{\mathrm{D}}=22$ & \\
\hline Mechanical quality factor $\mathrm{Q}_{\mathrm{m}}$ & $\mathrm{d}_{15}=1050 \mathrm{~d}_{33}=590 \mathrm{~d}_{31}=-270$ \\
\hline Elastic compliance constant $\left(10^{-12} \mathrm{~m}^{2} / \mathrm{N}\right)$ & & \\
\hline Piezoelectric strain constant $\left(10^{-12} \mathrm{C} / \mathrm{N}\right)$ & &
\end{tabular}

Table 1. The materials properties.

(a)

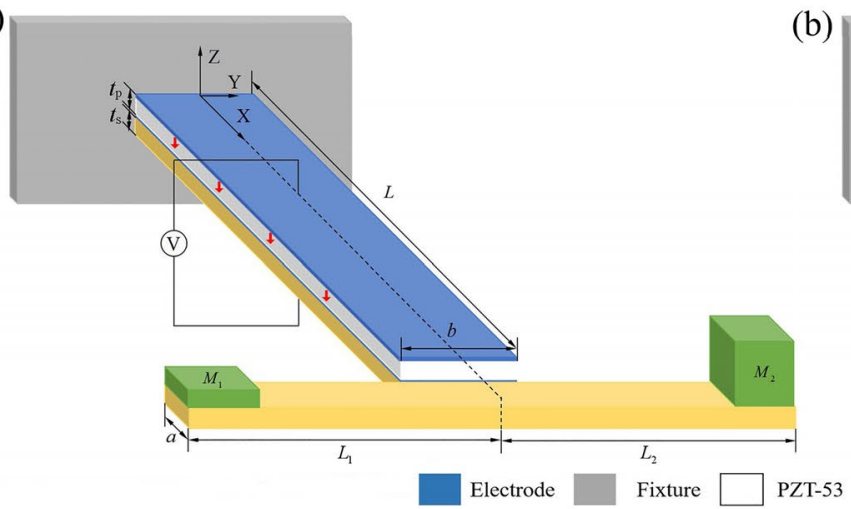

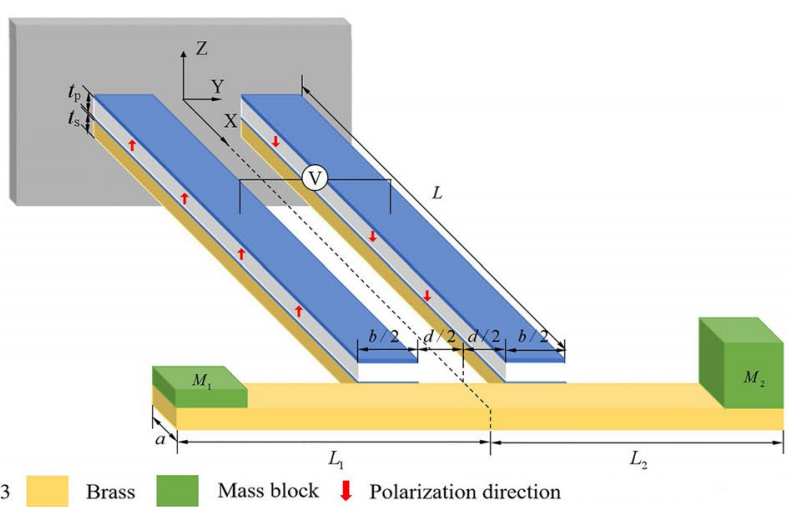

Figure 1. Schematics of PEH (a) SCB and (b) DCB undergoing coupled bending-torsion vibrations.

harvester for capturing wind energy at low wind speed is of lower natural frequency and smaller electromechanical coefficient than those of the conventional vortex-induced piezoelectric energy harvester ${ }^{18}$. The effect of width-splitting on the harvested power was theoretically and experimentally investigated for a fixed dimension piezoelectric materials of PEH undergoing bending vibration, and the width-splitting method could be used to increase the harvested voltage ${ }^{19}$ and power ${ }^{20}$ over a wider range of excitation frequencies. The single piezoelectric beam with the similar total width was folded equally and then split a given dimension of piezoelectric materials with the predefined dimensions into the array of smaller-width beams, and there is a substantial increase in harvested power ${ }^{21}$. There are many reports on the evaluation methods of half-power bandwidth and quality factor for PEHs undergoing bending vibration ${ }^{19,21}$, however relatively few researches are focus on the evaluation method for PEH undergoing coupled bending-torsion vibrations. The best performance occurs at a single or very narrow frequency range for most resonating harvesters, and then a critical issue is how to adjust the resonance frequency $\left(f_{0}\right)$ flexibility and maximize harvesting power because of environment vibrations composed of some broadband random or multiple-frequency excitation ${ }^{22,23}$. In a word, the width-splitting method could be used to improve energy harvesting performances of PEH undergoing bending vibration, however one could not know whether it is applicable to harvest more ambient energy from multiple-frequency excitation by using PEH undergoing coupled bending-torsion vibrations.

In this paper, $\mathrm{PEH}$ with single-cantilever-beam (SCB) is equally split into $\mathrm{PEH}$ with double-cantilever-beam (DCB) in order to harvest ambient energy from multiple-frequency excitation, which is verified comparing with the experimental and simulation results of the $\mathrm{U}_{\mathrm{p} \text {-max }}$ and $\Delta f_{0}$. After the geometrical dimensions including the split gap $d$, primary beam $L$ and substrate thickness $t_{\mathrm{s}}$ were determined by using $\mathrm{U}_{\mathrm{p} \text {-max }}$ and $\Delta f_{0}$ combination in multi-factors analysis based on orthogonal test method, we had fabricated PEHSCB and PEHDCB undergoing coupled bending-torsion vibrations. The mechanical vibration experiments were performed by shaker to measure $\mathrm{U}_{\mathrm{p}}$ vs frequency $\left(\mathrm{U}_{\mathrm{p}}-f\right)$ curves of PEHs undergoing coupled bending-torsion vibrations, and the half-power bandwidth proportion and materials mechanical quality factors are used to evaluate the harvesting efficiency from the multiple-frequency excitation. We expect that the research could significantly offer some useful guidelines to design high-performance $\mathrm{PEH}$, which could harvest more ambient energy under multiple-frequency excitation.

\section{Design and simulation}

Construction of PEHDCB split from PEHSCB. The single/double T-shaped brass shims and commercial piezoelectric ceramic PZT bulks were provided by Wuxi Hui Feng Electronics Co. Ltd, and the material properties parameters ${ }^{24-26}$ are listed in Table 1. PZT element was formed of PZT wafer, top and bottom electrodes, before PEHSCB was designed by bonding the elements on the primary beam via conductive adhesive, as shown in Fig. 1a. PEHDCB is constructed by splitting equally the primary beam of PEHSCB, as shown in Fig. 1b, and the split gap $d$ determined by the width-splitting method ${ }^{19,21}$ is listed in Table 2. 


\begin{tabular}{|l|l|l|l|l|l|l|l|}
\hline$d(\mathbf{m m})$ & $L(\mathbf{m m})$ & $\boldsymbol{t}_{\mathrm{s}}(\mathbf{m m})$ & $\boldsymbol{m}^{*}$ & $\boldsymbol{t}_{\mathrm{p}}(\mathbf{m m})$ & $L_{1} / L_{2}(\mathbf{m m})$ & $\boldsymbol{a}(\mathbf{m m})$ & $b(\mathbf{m m})$ \\
\hline $2-6$ & $26-30$ & $0.4-0.8$ & $0-19$ & 0.4 & 22 & 6 & 12 \\
\hline
\end{tabular}

Table 2. The geometrical dimensions.

There are two variable mass blocks $M_{2}$ and $M_{1}$ placed at tip of the crossbeam, and $M_{2} / M_{1}$ is defined as the mass ratio $m^{*}$ and when the mass ratio changes, the mass sum of mass blocks remains unchanged at both of the beam ends. The geometrical dimensions of PEHSCB include the length $L$, width $b$, thickness $t_{\mathrm{s}}$, piezoelectric ceramic thickness $t_{\mathrm{p}}$ for the primary beam and the length $L_{1}, L_{2}$, width $a$, mass ratio $m^{*}$ for the crossbeam, and all of them are listed in Table 2. The polarization direction of piezoelectric ceramic PZT-53 bulk is marked by the red arrows along Z-axis. Learning from the series connection structure ${ }^{27}$, two PZT elements split from the primary beam of PEHSCB are poled oppositely in the perpendicular to length direction to form the series connection shown in Fig. 1b. In Cartesian coordinate system (X, Y, Z), one ends of the single and double beams are fixed, and the crossbeams are at free end.

Simulation. Modeling on PEHSCB and PEHDCB. The $\mathrm{U}_{\mathrm{p}}$ and $f_{0}$ of PEHs are simulated by using the commercial analysis package ANSYS. The 8-node hexahedral coupled-field element SOLID5 and the 8-node linear structural element SOLID45 are used for piezoelectric materials and non-piezoelectric materials, and piezoelectric circuit element CIRCU94 is used for load resistor. The displacement degrees of freedom are constrained to be zero for fixed end of the primary beam of PEH. The electrode connections are made by using the "couple" commands $s^{28}$. As for PEHDCB, the potentials of top surface of substrate layer are coupled with bottom surface of piezoelectric layer, and they are individually coupled for top surfaces of two piezoelectric layers. The potential is constrained to be zero for one top surface of piezoelectric layers, and a load resistor is connected between the top surfaces of two piezoelectric layers, as shown in Fig. 1. The output voltage across load resistor is solved for the potential of top surface of piezoelectric layer, when T-shaped beam is loaded with the inertial acceleration $9.8 \mathrm{~m} / \mathrm{s}^{2}$.

In order to obtain a convergent solution by using mesh refinement ${ }^{29}$, the modal stress diagrams at the first mode of PEHDCB are performed by considering the four different mesh densities $0.7,0.6,0.5$ and $0.4 \mathrm{~mm}$, and they are respectively given as in Fig. 2a,b,c,d. Obviously, the difference of the maximum stress is less than $6 \%$ for the last two mesh densities, as shown in Fig. 2c,d, therefore it could be regarded as a convergent solution when mesh density $0.5 \mathrm{~mm}$.

The modal stress analysis. In order to satisfy the yield strength of piezoelectric materials and brass ${ }^{30}$, the modal analyses on PEHs with asymmetric mass are performed under the mesh density $0.5 \mathrm{~mm}$, and the modal stress diagrams are presented in Fig. 3a,b for PEHSCB and Fig. 3c,d for PEHDCB. Obviously, the maximum stresses of piezoelectric layer 37.3 MPa and brass layer $163 \mathrm{MPa}$ occur at the first mode for PEHDCB as shown in Fig. 3c, and they are smaller than the yield strengths of $60 \mathrm{MPa}$ and $200 \mathrm{MPa}$, indicating yield strength reliability.

Optimization on asymmetry PEHs with the different mass ratios. To investigate the effect of $m^{*}$ on the harvesting performance of PEHSCB, the $\mathrm{U}_{\mathrm{p}}-f$ curves were simulated under the different mass ratios $m^{*}=19,9,4$ and 1.5 when $b=12 \mathrm{~mm}, L_{1}=L_{2}=22 \mathrm{~mm}$, and they are described as Fig. 4 a. With the asymmetry increase of $m^{*}$ from 1.5 to 19 , the $\mathrm{U}_{\mathrm{p}-\max 1}$ and $f_{01}$ at the first mode decrease from 33.6 to $29.0 \mathrm{~V}$ and 88 to $72 \mathrm{~Hz}$. On the contrary, the $\mathrm{U}_{\mathrm{p}-\max 2}$ and $f_{02}$ at the second mode increase from 5.1-11.6 V and 118 to $177 \mathrm{~Hz}$. As for $m^{*}>1$, all of the $f_{01}$ and $f_{02}$ are far lower than the nature frequency $200 \mathrm{~Hz}$ and the $\Delta f_{0}$ is narrowed. Therefore it allows the harvesting of electrical power from the multiple-frequency excitation, and they are agreement with the previous results ${ }^{17}$. Drawing the $\mathrm{U}_{\mathrm{p}-\max }$ and $f_{0}$ at the certain $m^{*}$ from Fig. $4 \mathrm{a}$, the $\mathrm{U}_{\mathrm{p}-\max } \mathrm{vs} m^{*}$ and $f_{0}$ vs $m^{*}$ curves are described as Fig. $4 \mathrm{~b}$ for the first mode and Fig. $4 \mathrm{c}$ for the second mode. Both of the $\mathrm{U}_{\mathrm{p} \text {-max } 1}$ and $f_{01}$ decrease with the asymmetry increase of $m^{*}$, as shown in Fig. $4 \mathrm{~b}$, however the $f_{02}$ increases and the $\mathrm{U}_{\mathrm{p} \text {-max } 2}$ increases to reach a peak value at $m^{*}=9$ and then decreases by contrary, as shown in Fig. 4c. The optimization mass ratio $m^{*}$ is determined as 9 by considering the trade-off between $\mathrm{U}_{\mathrm{p}-\max }$ and $f_{0}$, in order that PEHSCB could achieve not only the higher $\mathrm{U}_{\mathrm{p}-\max }$ but also both the lower $f_{01}$ and $f_{02}$. According to the previous analysis method $^{31}$, we analogously determine the mass ratios $m^{*}=9$ to investigate harvest ambient energy of PEHDCB undergoing coupled bending-torsion vibrations from a multiple-frequency excitation as follow.

Effect of single-factor on PEHDCB. To understand the effect of single geometrical parameter on energy harvesting performance of PEHDCB, the $\mathrm{U}_{\mathrm{p}}-f$ curves were simulated under the different split gaps $d$, such as $2,3,4,5$ and $6 \mathrm{~mm}$, and they are described as Fig. $5 \mathrm{a}$ when $m^{*}=9, b=12 \mathrm{~mm}, L_{1}=L_{2}=22 \mathrm{~mm}$. With the $d$ increase from 2 to $6 \mathrm{~mm}$, the $\mathrm{U}_{\mathrm{p}-\max 1}, f_{01}$ and $f_{02}$ increase from 31.8 to $37.3 \mathrm{~V}, 75$ to $80 \mathrm{~Hz}$ and 167 to $177 \mathrm{~Hz}$ however the $\mathrm{U}_{\mathrm{p}-\max 2}$ decreases from 14.6 to $13.3 \mathrm{~V}$. The dependencies of $\mathrm{U}_{\mathrm{p} \text {-max }}$ and $f_{0}$ on $\mathrm{m}^{*}$ are analogously discussed as shown in Fig. $4 \mathrm{~b}, \mathrm{c}$, and the $\mathrm{U}_{\mathrm{p} \text {-max }}$ and $f_{0}$ vs $d$ curves are described as Fig. $5 \mathrm{~b}$ for the first mode and Fig. $5 \mathrm{c}$ for the second mode. With the increase of $d$, both of the $\mathrm{U}_{\mathrm{p} \text {-max } 1}$ and $f_{01}$ increase monotonously, however the $\mathrm{U}_{\mathrm{p}-\max 2}$ decreases and the $f_{02}$ increases by contrary. By adjusting the split gap $d$, PEHDCB can harvest energy more evenly at the two first modes, and it is in an agreement with the reported result ${ }^{32}$.

The $\mathrm{U}_{\mathrm{p}}-f$ curves were simulated under the different primary beam lengths $L$, such as $26,27,28,29$ and $30 \mathrm{~mm}$, $L_{1}=L_{2}=22 \mathrm{~mm}$, and they are described as Fig. $6 \mathrm{a}$ when $m^{*}=9, b=12 \mathrm{~mm}$. The $d$ dependencies of $\mathrm{U}_{\mathrm{p}-\max }$ and $f_{0}$ are analogously discussed, as shown in Fig. $5 \mathrm{~b}, \mathrm{c}$, and the $\mathrm{U}_{\mathrm{p}-\max }$ and $f_{0} \mathrm{vs} L$ curves are described as Fig. $6 \mathrm{~b}$ for the 

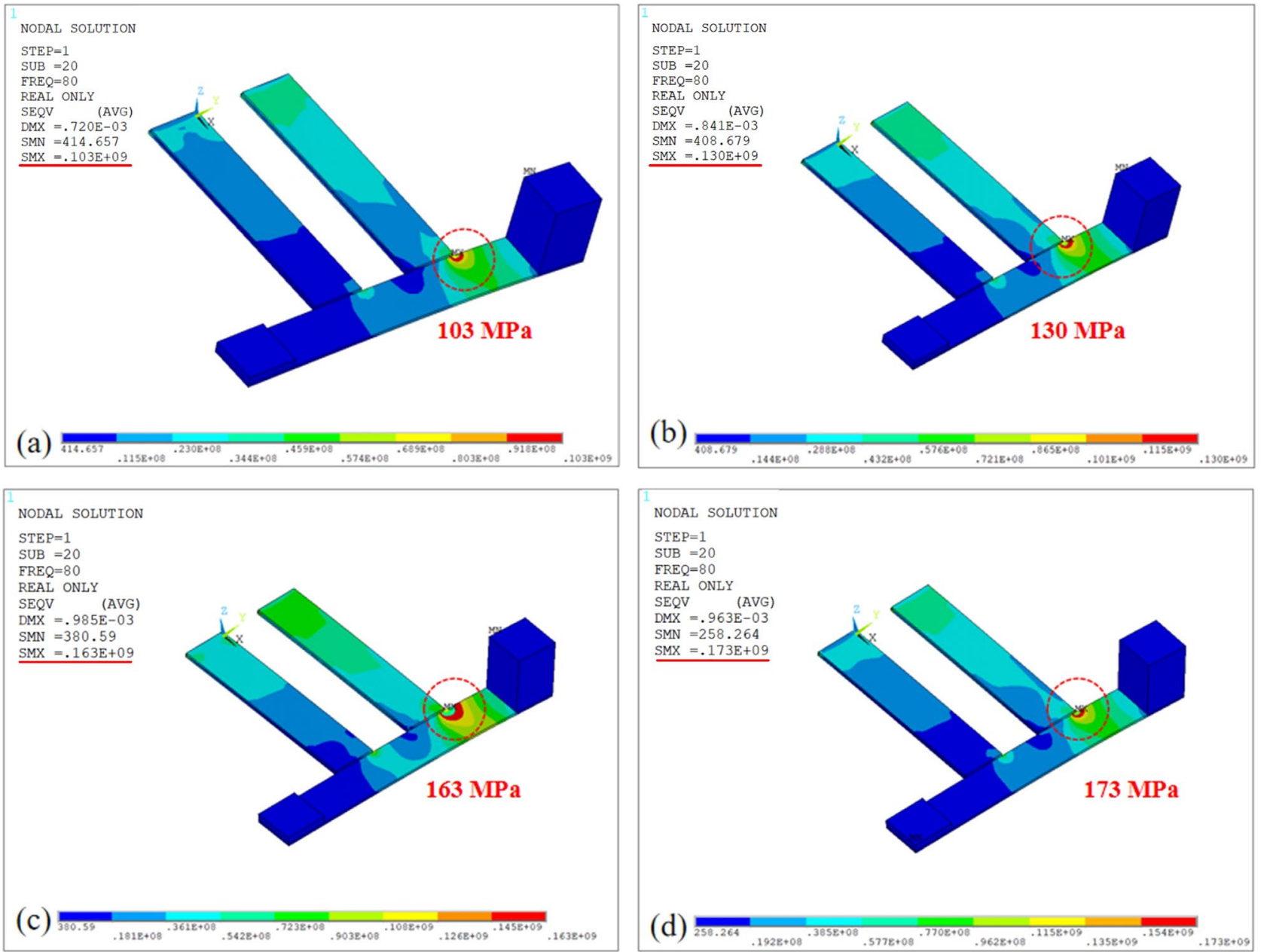

Figure 2. The modal stress diagrams of convergent judge at the mesh densities for PEHDCB (a) 0.7, (b) 0.6, (c) 0.5 and (d) $0.4 \mathrm{~mm}$.

first mode and Fig. $6 \mathrm{c}$ for the second mode. With the increase of $L$, the $\mathrm{U}_{\mathrm{p} \text {-max } 1}$ monotonously increases but the $\mathrm{U}_{\mathrm{p}-\max 2}$ slightly decreases at the second mode, however both of the $f_{01}$ and $f_{02}$ decrease. It indicates that the primary beam length can be adjusted by considering the trade-off between the $\mathrm{U}_{\mathrm{p} \text {-max }}$ and $f_{0}$, in order that PEHDCB could harvest energy more evenly under the multiple-frequency excitation.

The $\mathrm{U}_{\mathrm{p}}-f$ curves were simulated under the different substrate thicknesses $t_{s}$, such as $0.4,0.5,0.6,0.7$ and $0.8 \mathrm{~mm}$, and they are described as Fig. $7 \mathrm{a}$, when $m^{*}=9, b=12 \mathrm{~mm}, L_{1}=L_{2}=22 \mathrm{~mm}$. Analogously, the $\mathrm{U}_{\mathrm{p}-\max }$ and $f_{0}$ vs $t_{\mathrm{s}}$ curves are described as Fig. $7 \mathrm{~b}$ for the first mode and Fig. $7 \mathrm{c}$ for the second mode. With the increase of $t_{\mathrm{s}}$, the $\mathrm{U}_{\mathrm{p}-\max 1}$ increases to reach the peak at $t_{s}=0.6 \mathrm{~mm}$ however the $\mathrm{U}_{\mathrm{p} \text {-max } 2}$ decreases monotonously. Both the $f_{01}$ and $f_{02}$ increase. It could guide to choose a suitable $t_{\mathrm{s}}$ to achieve high $\mathrm{U}_{\mathrm{p} \text {-max }}$ and low $f_{0}$ of PEHDCB under the multiple-frequency excitation.

Multi-factor analysis via orthogonal test method. Generally, the effect of single-factor on performance of PEHDCB could not be taken into account the cross factor effect ${ }^{33}$, therefore we carry out the multifactors analysis to optimize energy harvesting performance of PEHDCB by using orthogonal test method. The orthogonal factor/level list and the $\mathrm{L}_{25}\left(5^{6}\right)$ corresponding orthogonal list are shown in Tables 3 and 4.

There are the three geometrical dimensions $d, t_{\mathrm{s}}$ and $L$ corresponding to 5 levels in Table 3. Distinguished from the traditional orthogonal test $\operatorname{method}^{8}$, the $\mathrm{U}_{\mathrm{p}-\max 1}, \mathrm{U}_{\mathrm{p}-\max 2}$ and $\Delta f_{0}$ were chosen as the optimization objectives to analyze the influences of the three factors on the performance, and the last three factors are kept empty corresponding to the $\mathrm{L}_{25}\left(5^{6}\right)$ lists in Table $4^{34}$. As for the optimal combination of Case 21 in Table 4 , the $\mathrm{U}_{\mathrm{p} \text {-max }}$ and $\mathrm{U}_{\mathrm{p}-\max 2}$ are $37.3 \mathrm{~V}$ and $13.3 \mathrm{~V}$, and the $\Delta f_{0}$ is $97.0 \mathrm{~Hz}$. Correspondingly, the $d, L$ and $t_{\mathrm{s}}$ are optimally determined as 6,30 , and $0.4 \mathrm{~mm}$, in order that PEHDCB achieves not only high $\mathrm{U}_{\mathrm{p} \text {-max }}$ but also narrow $\Delta f_{0}$ for easily harvesting electrical power from the multiple-frequency excitation ${ }^{17}$.

\section{Experiment}

Experimental measurement. The mechanical vibration experiment was carried out to verify the validity and accuracy of simulation result, and the schematic diagram and power measurement circuit are given in Fig. $8 \mathrm{a}, \mathrm{b}$ for the measurement setup ${ }^{27}$. In order to investigate the effect of width splitting method on the 

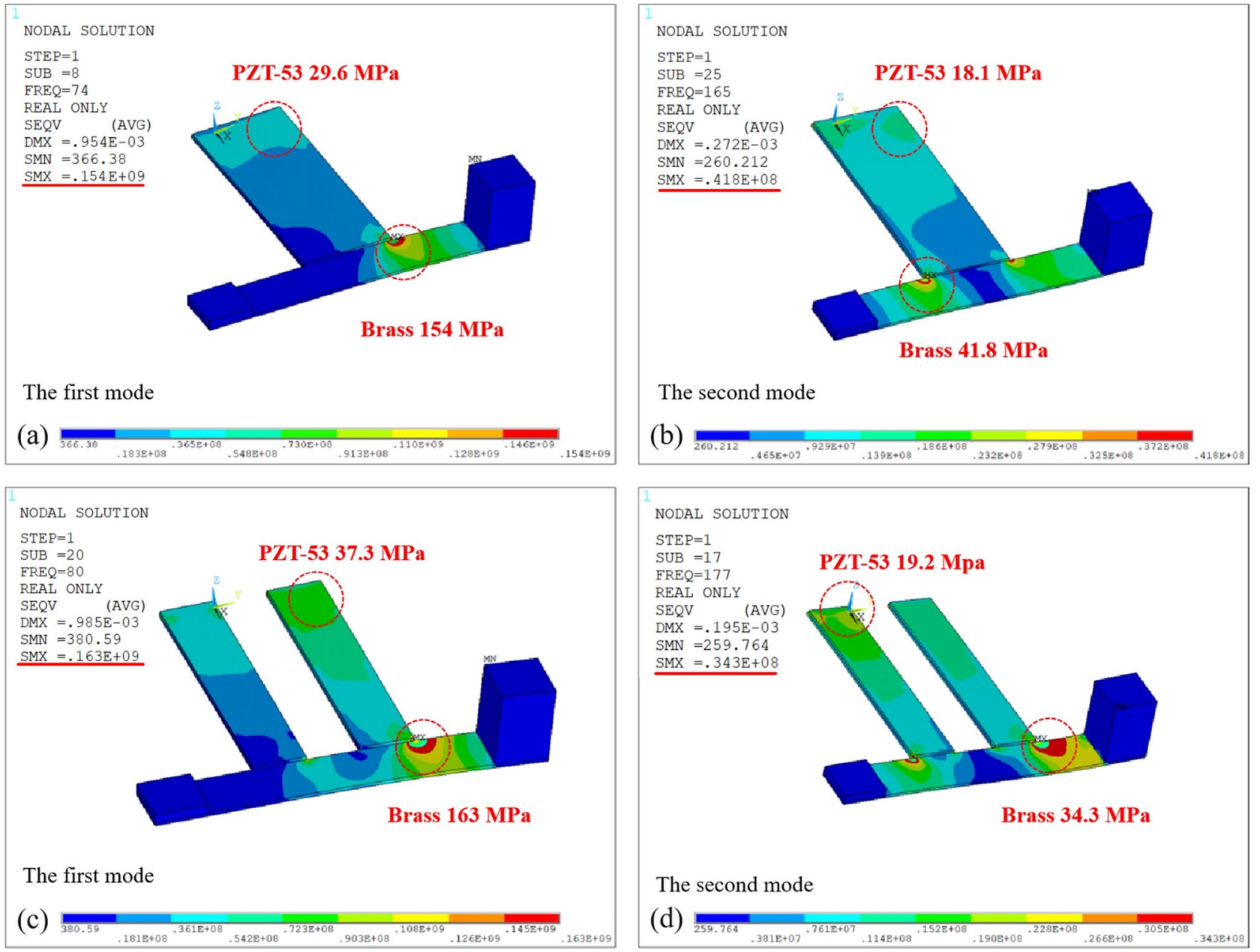

The second mode

(d)

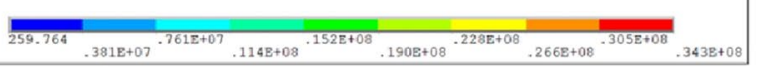

Figure 3. The modal stress diagrams of yield strength (a,b) for PEHSCB and (c,d) for PEHDCB.

energy harvesting performances, PEHDCB was constructed by splitting equally the primary beam, and both of PEHSCB and PEHDCB were fabricated according to the optimal combination Case 21 in Table 4, as shown in Fig. 8c,d. After clamped by the fixtures, PEHSCB and PEHDCB were fixed on the shaker (JZk-5, Sinocera Piezotronics, Inc., Jiangsu, China), and the acceleration was obtained through the accelerometer (CA-DR-005, Sinocera Piezotronics, Inc., Jiangsu, China) placed on the top of the shaker. The sinusoidal vibration from the function generator (Tektronix AFG 3021B, Tektronix) was amplified by the power amplifier (YE5871A, Sinocera Piezotronics, Inc., Jiangsu, China), and the shaker was applied at $2.1 \mathrm{~A}$ and $1 \mathrm{~V}$ to generate the mechanical energy.

All the output peak voltages of PEHSCB and PEHDCB were measured at the certain resistance of $100 \mathrm{k} \Omega$ by Digital Oscilloscope (Tektronix TDS 1002, Tektronix), and the output power was calculated by using the formula $P=U_{P}^{2} / 2 R_{L}{ }^{24}$, where $R_{L}$ the load resistance. Generally, the proportion of half-power bandwidth and the quality factor $\left(\mathrm{Q}=f_{0} / \delta_{f}\right)$ are used to evaluate the collection efficiencies of PEHDCB under a single-frequency excitation and multi-frequency excitation ${ }^{19,21}$, and the $\delta_{f}$ is the $3 \mathrm{~dB}$ bandwidth of PEHDCB ${ }^{35}$.

Test and verify on energy harvesting efficiency of PEHSCBs. The energy harvesting efficiency of PEHSCB undergoing coupled bending- torsion vibrations is better than that of PEHSCB undergoing bending vibration in the simulation results ${ }^{24}$, therefore we hope to verify the previous results by comparing with the $\Delta f_{0}$ and proportion of half-power bandwidth in the mechanical vibration experiment as follow. The output peak voltages were measured under $b=12 \mathrm{~mm}, L_{1}=L_{2}=22 \mathrm{~mm}, \mathrm{R}_{\mathrm{L}}=100 \mathrm{k} \Omega$, and the $\mathrm{U}_{\mathrm{p}}-f$ and P- $f$ curves are given in Fig. 9a,b for PEHSCBs undergoing coupled bending-torsion vibrations with $m^{*}=9$ and bending vibration with $m^{*}=1$. Here, the simulation results are represented by the solid lines, and the experimental results are described by the dots for the latter and the triangles for the former. From Fig. 9a, the $f_{01}$ of PEHSCB with $m^{*}=9$ is lower than that of PEHSCB with $m^{*}=1$, which indicates that PEH undergoing coupled bending-torsion vibrations is more suitable for harvesting the electrical power from the ambient vibration composed of low frequency ${ }^{36}$. On the other hand, the $\Delta f_{0}$ is $90.0 \mathrm{~Hz}$ for PEHSCB undergoing coupled bending-torsion vibrations, however it is far much narrower than that of PEHSCB undergoing bending vibration. Obviously, the coupled bending-torsion vibrations could decrease the $\Delta f_{0}$ to allow the harvesting of electrical power from the multiple- 

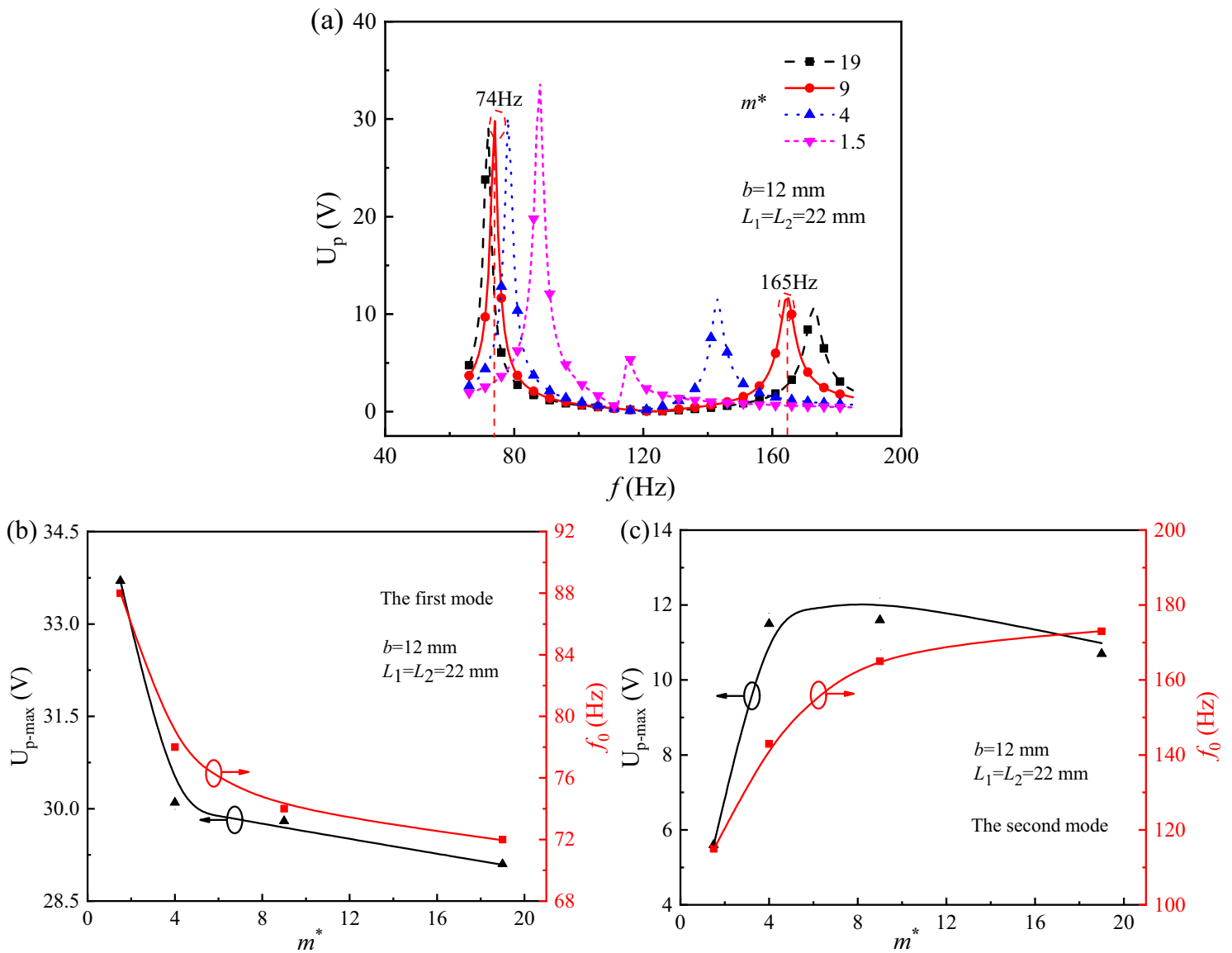

Figure 4. The $\mathrm{U}_{\mathrm{p}}-f$ curves (a), $\mathrm{U}_{\mathrm{p}-\max }$ and $f_{0}$ vs $m^{*}$ curves at the first (b) and second (c) modes of PEHSCB.

frequency excitation, and the results are similar with the experimental observations in the previous reports ${ }^{17,37}$. The energy harvesting efficiency could be generally evaluated by the half-power bandwidth value ${ }^{19,21}$, but the proportion of half-power bandwidth should be more suitable to evaluate the harvesting efficiency for $\mathrm{PEH}$ at the multiple-frequency excitation ${ }^{25}$. Here, the proportions of half-power bandwidth are $5.2 \%$ at the first mode and $3.8 \%$ and at the second mode for PEHSCB with $m^{*}=9$, and the proportion of half-power bandwidth is $5.1 \%$ at the first mode for PEHSCB with $m^{*}=1$. Obviously, the proportion of half-power bandwidth of PEHSCB undergoing coupled bending-torsion vibrations is superior to that of PEHSCB undergoing bending vibration at the first mode, meanwhile the former could far more easy to harvest the electrical power from the ambient vibration because of the resonance lack for the latter at the second mode. The energy harvesting efficiency of PEHSCB undergoing coupled bending-torsion vibrations must be much better than that of PEHSCB undergoing bending vibration, since the environmental vibrations are generally composed of the multiple-frequency.

Effect of width splitting method on the energy harvesting performances. In order to verify the effect of width splitting method on the energy harvesting performances ${ }^{19,21}$, the $\mathrm{U}_{\mathrm{p} \text {-max }}$ and $\mathrm{P}_{\mathrm{p} \text {-max }}$ of PEHDCB are compared with those of PEHSCB, meanwhile the quality factors related with $\Delta f_{0}$ are compared because of damping change induced width splitting method. The $\mathrm{U}_{\mathrm{p}-\max }$ were measured for PEHDCB with $d=6 \mathrm{~mm}, b=12 \mathrm{~mm}$, $L_{1}=L_{2}=22 \mathrm{~mm}, m^{*}=9, R_{\mathrm{L}}=100 \mathrm{k} \Omega$, and the $\mathrm{U}_{\mathrm{p}}-f$ and $\mathrm{P}-f$ curves are given in Fig. 10a,b for both of PEHSCB and PEHDCB. The simulation/experimental $U_{p-\max 1}$ and $U_{p-\max 2}$ results are $37.3 \mathrm{~V} / 35.1 \mathrm{~V}$ and $13.3 \mathrm{~V} / 12.1 \mathrm{~V}$ for PEHDCB, and they are $29.8 \mathrm{~V} / 28.4 \mathrm{~V}$ and $11.6 \mathrm{~V} / 10.7 \mathrm{~V}$ for PEHSCB. The $\mathrm{P}_{\mathrm{p}-\max 1}$ and $\mathrm{P}_{\mathrm{p}-\max 2}$ are $6.97 \mathrm{~mW} /$ $6.16 \mathrm{~mW}$ and $0.89 \mathrm{~mW} / 0.73 \mathrm{~mW}$ for PEHDCB, and they are $4.43 \mathrm{~mW} / 4.03 \mathrm{~mW}$ and $0.65 \mathrm{~mW} / 0.57 \mathrm{~mW}$ for PEHSCB. For the same undergoing coupled bending-torsion vibrations, the $U_{p-\max }$ and $P_{p-\max }$ of PEHDCB are obviously larger than those of PEHSCB, and they are agreement with the simulation reports ${ }^{19,21}$. As for the first and second modes, the simulation/experiment $\mathrm{Q}_{1}$ and $\mathrm{Q}_{2}$ results are 32.13/25.08 and 35.4/30.17 for PEHDCB, and they are 29.72/24.33 and 33.15/25.2 for PEHSCB. Obviously, the $\mathrm{Q}_{1}$ and $\mathrm{Q}_{2}$ of PEHDCB undergoing coupled bending-torsion vibrations are larger than those of PEHSCB undergoing bending vibration, and it indicates that the former could easily harvest the energy from the ambient vibration. In a word, all of the energy harvesting performances of PEHDCB undergoing coupled bending-torsion vibrations have been enhanced by the widthsplitting method. Our result shows that bending torsional coupled vibration $\mathrm{PEH}$ can harvest more power than bending vibration $\mathrm{PEH}$, which is consistent with the result reported ${ }^{38}$. 

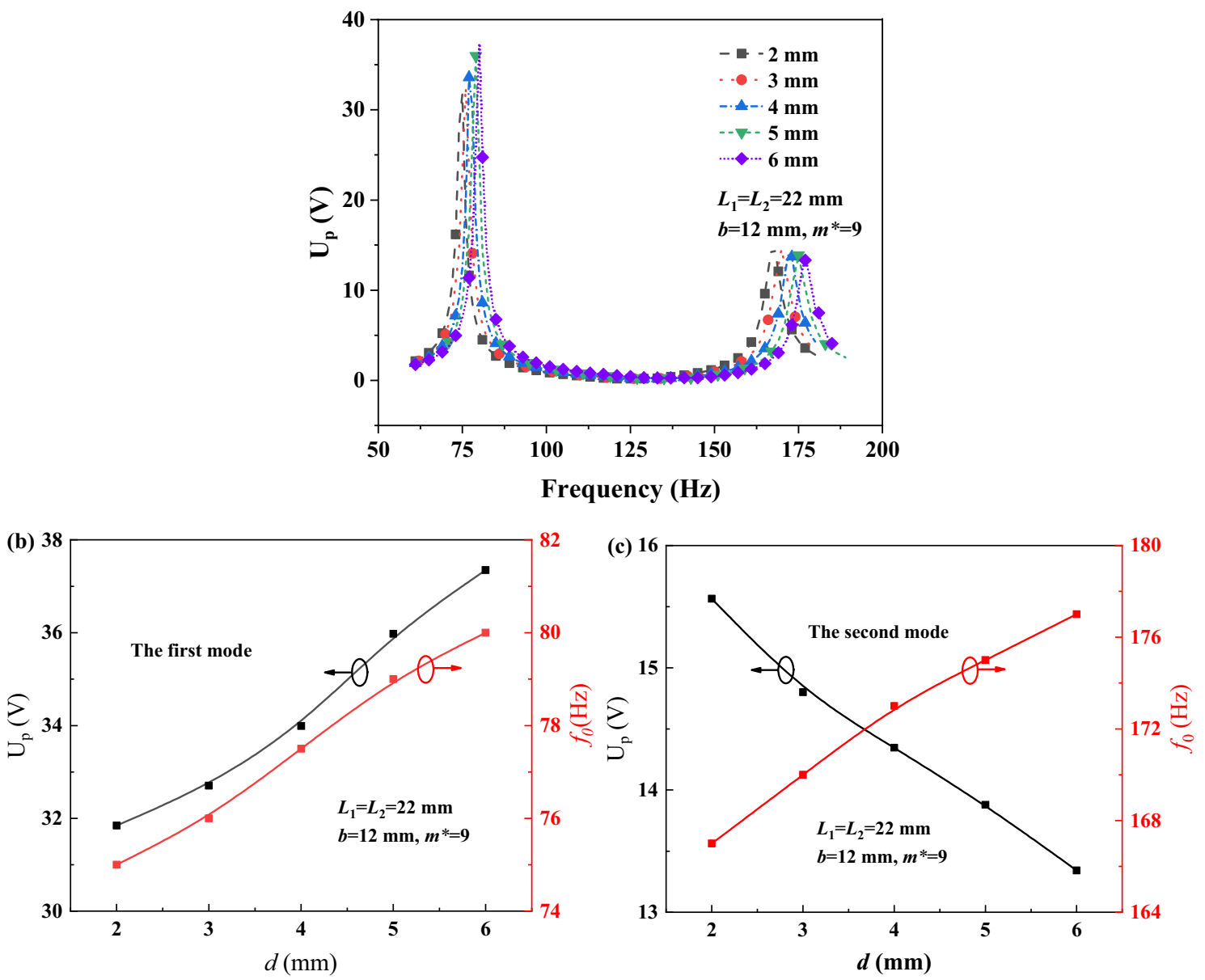

Figure 5. The $\mathrm{U}_{\mathrm{p}}-f$ curves (a), $\mathrm{U}_{\mathrm{p}-\max }$ and $f_{0}$ vs $m^{*}$ curves at the first (b) and second (c) modes.

Energy harvesting performances of asymmetry PEHDCBs. The $\mathrm{U}_{\mathrm{p}}-f$ curves of the PEHDCBs were measured under the different mass ratios $m^{*}$, such as 1.5, 4, 9 and 19, and they are given in Fig. 11, when $b=12 \mathrm{~mm}, L_{1}=L_{2}=22 \mathrm{~mm}, d=6 \mathrm{~mm}, \mathrm{R}_{\mathrm{L}}=100 \mathrm{k} \Omega$. Here, the simulation and experimental results are represented by the lines and dots, in order that the validity could be confirmed by analyzing the relative deviations of $\mathrm{U}_{\mathrm{p}-\max }$ and $f_{0}$ at the first and second modes. Obviously, the maximum relative deviations of $\mathrm{U}_{\mathrm{p}-\max }$ and $f_{0}$ are $6.8 \%$ and $2.6 \%$ for the first mode, and they are $14.2 \%$ and $2.5 \%$ for the second mode. There are generally the incomplete clamping of the experimental fixture and the unavoidable assembly errors in the manufacture ${ }^{39}$, therefore the simulation results could be not exactly equal to the resonance frequency experiment results for PEHs with the asymmetric mass and width-splitting beam in Figs. 8, 9 and 10. The clamped end of beam is not completely rigid in mechanical vibration experimental, however the fixed boundary conditions in simulation make the beam slightly stiffer. The incomplete clamping and inevitable assembly frequency errors are approximately at the ranges of $2-7 \%$ for the nonstable nonlinear energy harvester ${ }^{40,41}$ and $5-10 \%$ for the piezoelectric energy harvester for harnessing energy from flow-induced vibration ${ }^{39}$, and the $\mathrm{U}_{\mathrm{p}-\max }$ error is approximately at the range of $10-26 \%$ for the rotational mechanical plucking energy harvester ${ }^{42}$. The $\mathrm{U}_{\mathrm{p}-\max }$ and $f_{0}$ deviations are $14.2 \%$ and $2.6 \%$ for the PEHDCBs under the different mass ratios, as shown in Fig. 11, therefore the results are acceptable for the mechanical vibration experiment.

Drawn from Fig. 11, the $\mathrm{U}_{\mathrm{p}-\max }$ and $m^{*}$ are served as the vertical and horizontal ordinates to understand the effect of asymmetric mass on energy harvesting performance, and the $U_{p-\max 1}$ and $U_{p-\max 2}$ vs $m^{*}$ curves are described as Fig. 12. With the asymmetric increase of $m^{*}$ from 1.5 to 9 , the simulation/experimental $U_{p-\max 1}$ values decrease from $41.0 \mathrm{~V} / 38.2 \mathrm{~V}$ to $36.5 \mathrm{~V} / 34.8 \mathrm{~V}$, and the simulation/experimental $\mathrm{U}_{\mathrm{p} \text {-max2 }}$ values increase to the reach peak values of $13.3 \mathrm{~V} / 12.8 \mathrm{~V}$ and $12.1 \mathrm{~V} / 11.1 \mathrm{~V}$. Obviously, the energy harvesting efficiency is slightly decreased under the multiple-frequency excitation when the mass ratio $m^{*}$ is larger than 9. Considering the trade-off of $\mathrm{U}_{\mathrm{p}-\max 1}$ and $\mathrm{U}_{\mathrm{p}-\max 2}$, PEHDCB with $m^{*}=9$ can harvest energy more evenly, and it is similar with the reported result ${ }^{43}$. In a word, there is a useful strategy to enhance the $U_{p-\max 1}$ and $U_{p-\max 2}$ by adjusting the 

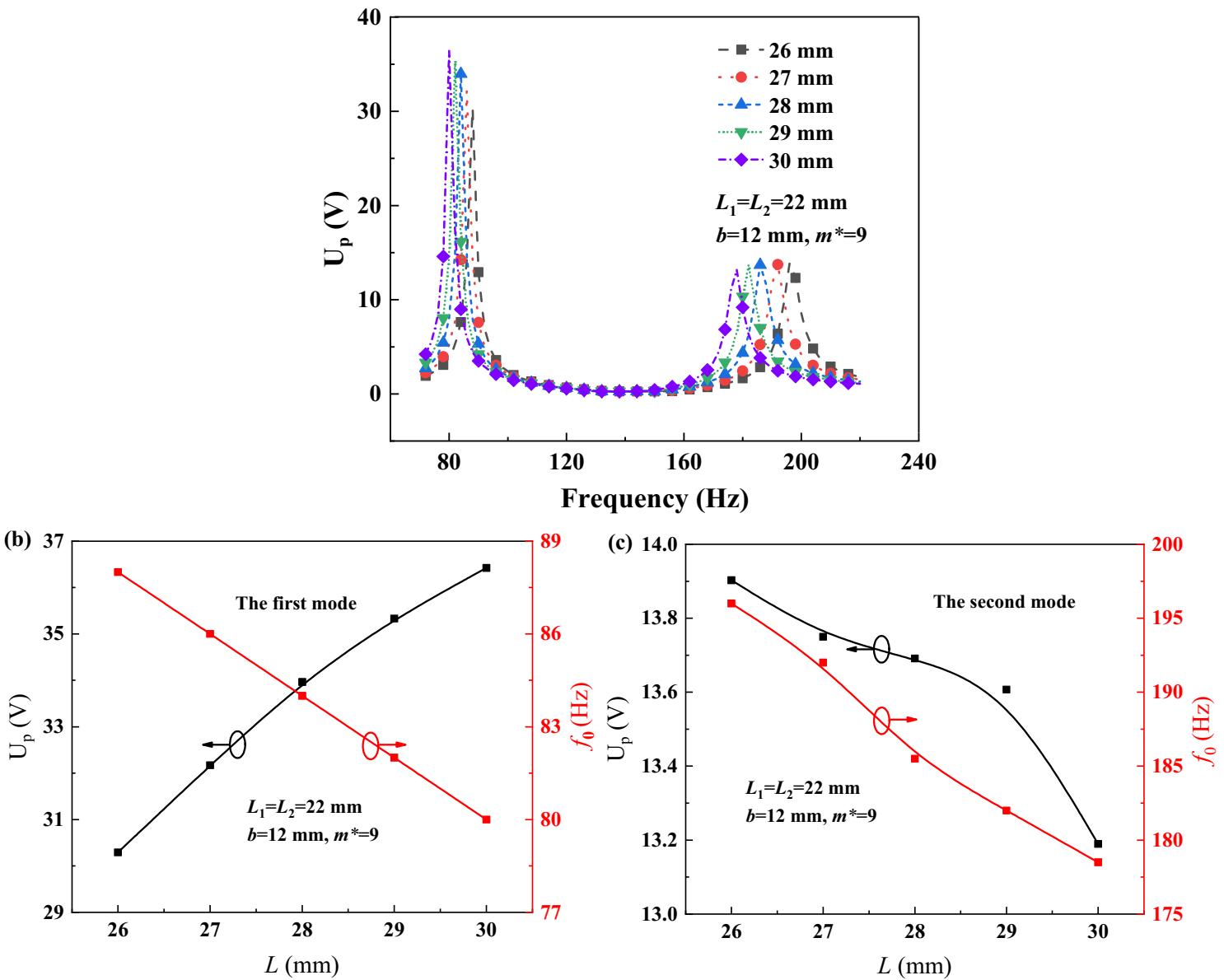

Figure 6. The $\mathrm{U}_{\mathrm{p}}-f$ curves (a), the $\mathrm{U}_{\mathrm{p}-\max }$ and $f_{0}$ vs $L$ curves at the first (b) and second (c) modes.

asymmetric mass ratio under the multiple-frequency excitation. There is an impact of fatigue life on the energy harvest from environmental vibration with a multiple-frequency excitation, and the fatigue life could be chosen as the indicative parameters at the multi-factors analysis the further work including experiment and simulation.

\section{Conclusion}

In summary, the optimization geometrical parameters of PEHDCB are determined by considering the $\mathrm{U}_{\mathrm{p} \text {-max }}$ and $\Delta f_{0}$ in the multi-factor analysis based on the orthogonal test, and the $\Delta f_{0}$ narrowed of PEHDCB undergoing coupled bending-torsion vibrations results in harvesting the more electrical power from the ambient vibration composed of low frequency. The quality factors $\mathrm{Q}_{1}$ and $\mathrm{Q}_{2}$ of $\mathrm{PEHDCB}$ undergoing coupled bending-torsion vibrations are larger than those of PEHSCB under the multi-frequency excitation, and the $\mathrm{U}_{\mathrm{p}-\max 1}$ and $\mathrm{P}_{\mathrm{p}-\max 1}$ at the first mode are increased $25.2 \%$ and $57.3 \%$ for PEHDCB. The width-splitting method could be successfully used to improve the energy harvesting performances, and the measurement reliability is acceptable considering the incomplete clamping, damping and inevitable assembly effects. Considering the trade-off of $U_{p-m a x 1}$ and $\mathrm{U}_{\mathrm{p}-\max 2}$, the asymmetry PEHDCB with the mass ratio determined as 9 can harvest energy more evenly, and the results are effective to predict the energy harvesting performances for PEHDCB undergoing coupled bendingtorsion vibrations under the multi-frequency excitation. As for the purpose to explore the effect of width splitting method on the energy harvesting performances in this work, we should consider the parameters related with damping change such as the width splitting size $d$ into electromechanical coupling dynamic equation, and one could obtain a closed form solution and comparing to give better insights on how the harvested power varies by varying the parameters in future research. 

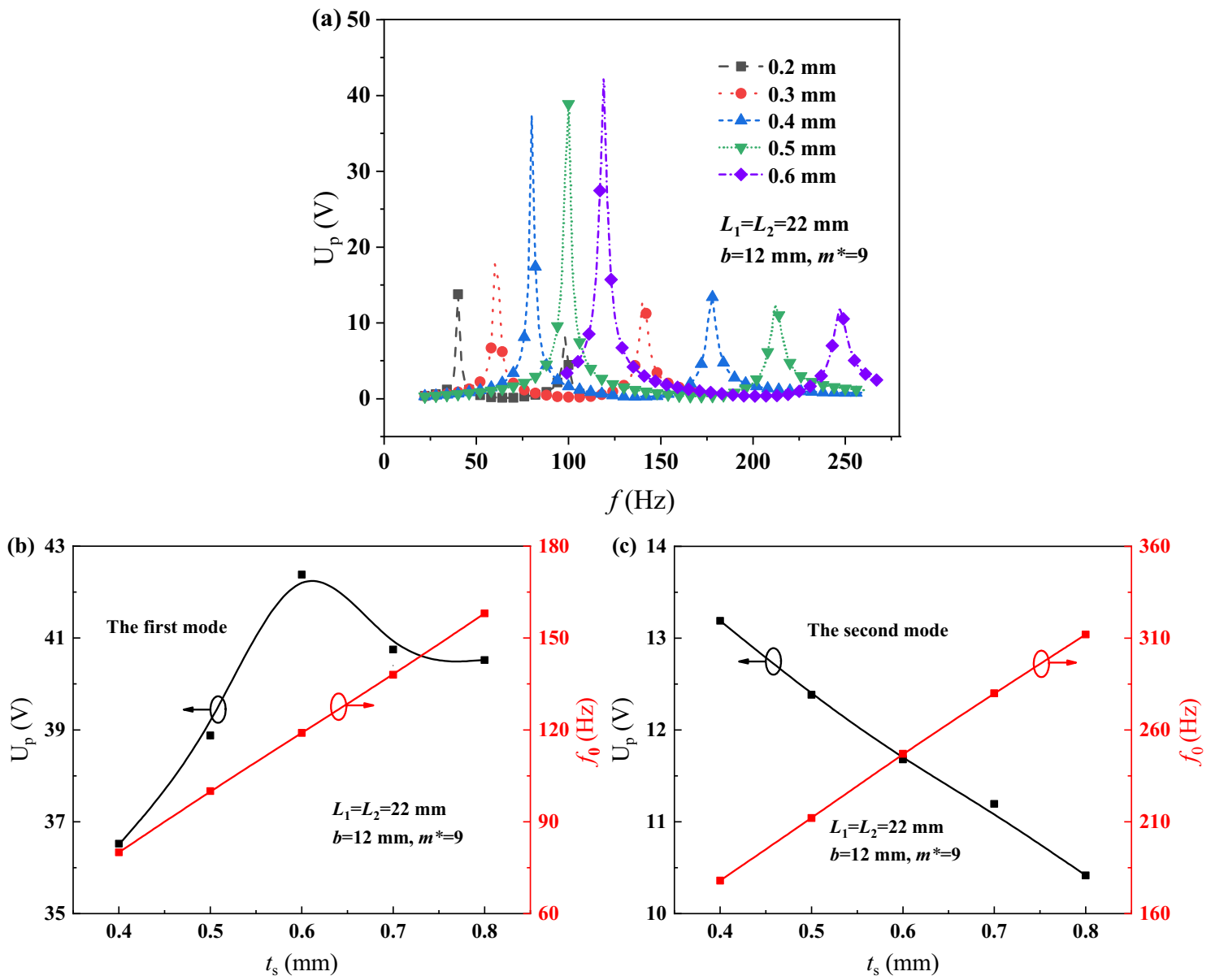

Figure 7. The $\mathrm{U}_{\mathrm{p}}-f$ curves (a), the $\mathrm{U}_{\mathrm{p}-\max }$ and $f_{0}$ vs $t_{s}$ curves at the first (b) and second (c) modes of PEHDCB.

\begin{tabular}{|l|l|l|l|l|l|}
\hline \multirow{2}{*}{ Factor } & \multicolumn{4}{|l|}{ Level } \\
\cline { 2 - 7 } & $\mathbf{1}$ & $\mathbf{2}$ & $\mathbf{3}$ & $\mathbf{4}$ & $\mathbf{5}$ \\
\hline$d(\mathrm{~mm})$ & 2 & 3 & 4 & 5 & 6 \\
\hline$t_{\mathrm{s}}(\mathrm{mm})$ & 0.4 & 0.5 & 0.6 & 0.7 & 0.8 \\
\hline$L(\mathrm{~mm})$ & 26 & 27 & 28 & 29 & 30 \\
\hline
\end{tabular}

Table 3. The orthogonal factor and level list. 


\begin{tabular}{|c|c|c|c|c|c|c|}
\hline \multirow[b]{2}{*}{ Cases } & \multicolumn{3}{|l|}{ Factor } & \multirow[b]{2}{*}{$\Delta f_{0}(\mathrm{~Hz})$} & \multirow[b]{2}{*}{$\mathrm{U}_{\mathrm{p}-\max \mathbf{1}}(\mathrm{V})$} & \multirow[b]{2}{*}{$\mathrm{U}_{\mathrm{p}-\max 2}(\mathrm{~V})$} \\
\hline & $d(\mathrm{~mm})$ & $t_{\mathrm{s}}(\mathrm{mm})$ & $L(\mathrm{~mm})$ & & & \\
\hline 1 & 2 & 0.4 & 26 & 104.9 & 25 & 14.7 \\
\hline 2 & 2 & 0.5 & 27 & 117.2 & 33.4 & 14.2 \\
\hline 3 & 2 & 0.6 & 28 & 128 & 37.5 & 14.2 \\
\hline 4 & 2 & \begin{tabular}{|l|}
0.7 \\
\end{tabular} & 29 & 137.2 & 34.4 & 12.5 \\
\hline 5 & 2 & \begin{tabular}{|l|}
0.8 \\
\end{tabular} & 30 & 145.5 & 40.4 & 12.3 \\
\hline 6 & 3 & 0.4 & 27 & 102.7 & 28.6 & 14.6 \\
\hline 7 & 3 & 0.5 & 28 & 115 & 34.4 & 14.2 \\
\hline 8 & 3 & \begin{tabular}{|l|}
0.6 \\
\end{tabular} & 29 & 126.1 & 38.7 & 13.5 \\
\hline 9 & 3 & \begin{tabular}{|l|}
0.7 \\
\end{tabular} & 30 & 135.7 & 41.6 & 12.4 \\
\hline 10 & 3 & 0.8 & 26 & 163.1 & 35.6 & 13.2 \\
\hline 11 & 4 & 0.4 & 28 & 100.7 & 31.4 & 14.5 \\
\hline 12 & 4 & 0.5 & 29 & 113.1 & 38.0 & 13.7 \\
\hline 13 & 4 & 0.6 & 30 & 124.6 & 41.7 & 12.8 \\
\hline 14 & 4 & \begin{tabular}{|l|}
0.7 \\
\end{tabular} & 27 & 148 & 37.0 & 13.1 \\
\hline 15 & 4 & 0.8 & 26 & 134.6 & 32.7 & 12.0 \\
\hline 16 & 5 & 0.4 & 29 & 99 & 34.8 & 13.9 \\
\hline 17 & 5 & 0.5 & 30 & 111.7 & 40.0 & 12.8 \\
\hline 18 & 5 & 0.6 & 28 & 132.6 & 38.3 & 13.0 \\
\hline 19 & 5 & 0.7 & 27 & 149.8 & 37.4 & 12.7 \\
\hline 20 & 5 & 0.8 & 26 & 167 & 35.8 & 12.5 \\
\hline 21 & 6 & 0.4 & 30 & 97.0 & 37.3 & 13.3 \\
\hline 22 & 6 & 0.5 & 28 & 118.8 & 35.5 & 14.0 \\
\hline 23 & 6 & 0.6 & 27 & 138 & \begin{tabular}{|l|}
36.4 \\
\end{tabular} & 13.8 \\
\hline 24 & 6 & \begin{tabular}{|l|}
0.7 \\
\end{tabular} & 26 & 156.1 & 36.2 & 12.5 \\
\hline 25 & 6 & \begin{tabular}{|l|}
0.8 \\
\end{tabular} & 29 & 157.1 & 40.8 & 10.8 \\
\hline
\end{tabular}

Table 4. $\mathrm{L}_{25}\left(5^{6}\right)$ orthogonal list. 
(a)

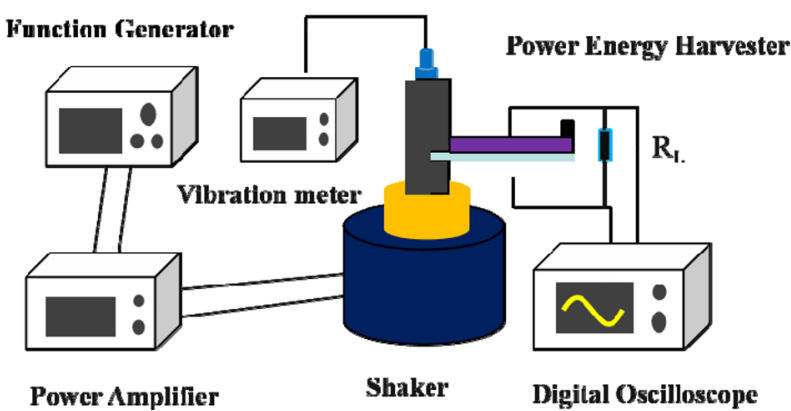

(c)

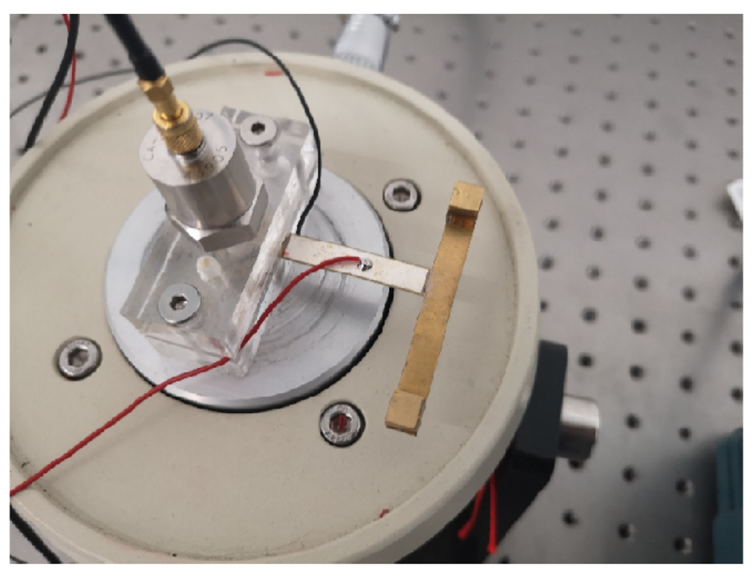

(b)

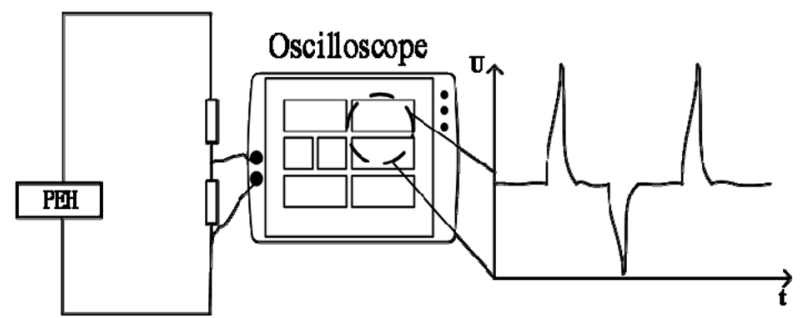

(d)

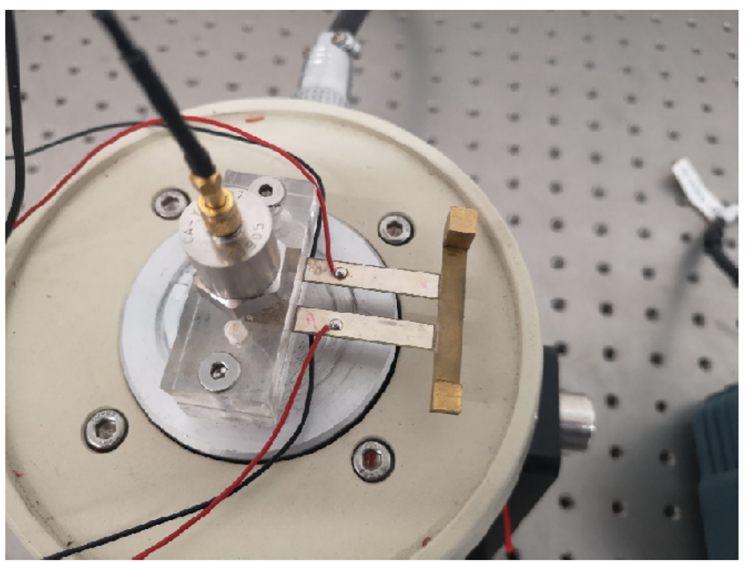

Figure 8. Schematic diagram (a). Power measurement circuit (b). The vibration component prototypes of PEHSCB (c) and PEHDCB (d).
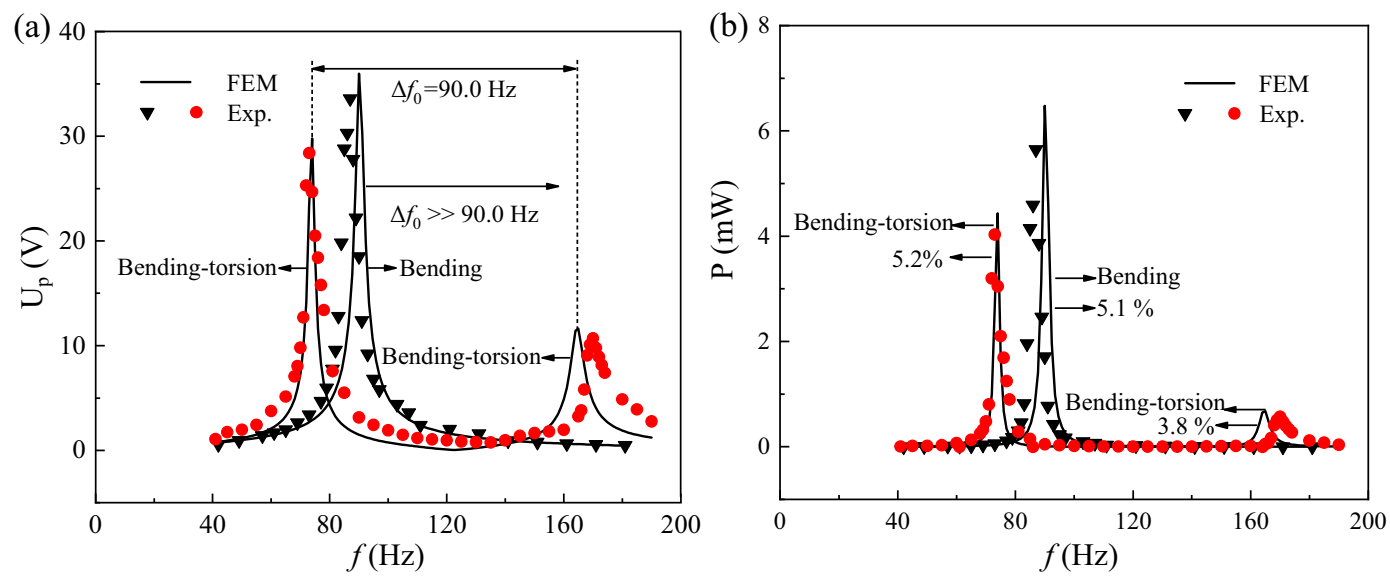

Figure 9. The $\mathrm{U}_{\mathrm{p}}-f(\mathbf{a})$ and $\mathrm{P}-f(\mathbf{b})$ curves of PEHSCBs undergoing coupled bending-torsion vibrations and bending vibration. 

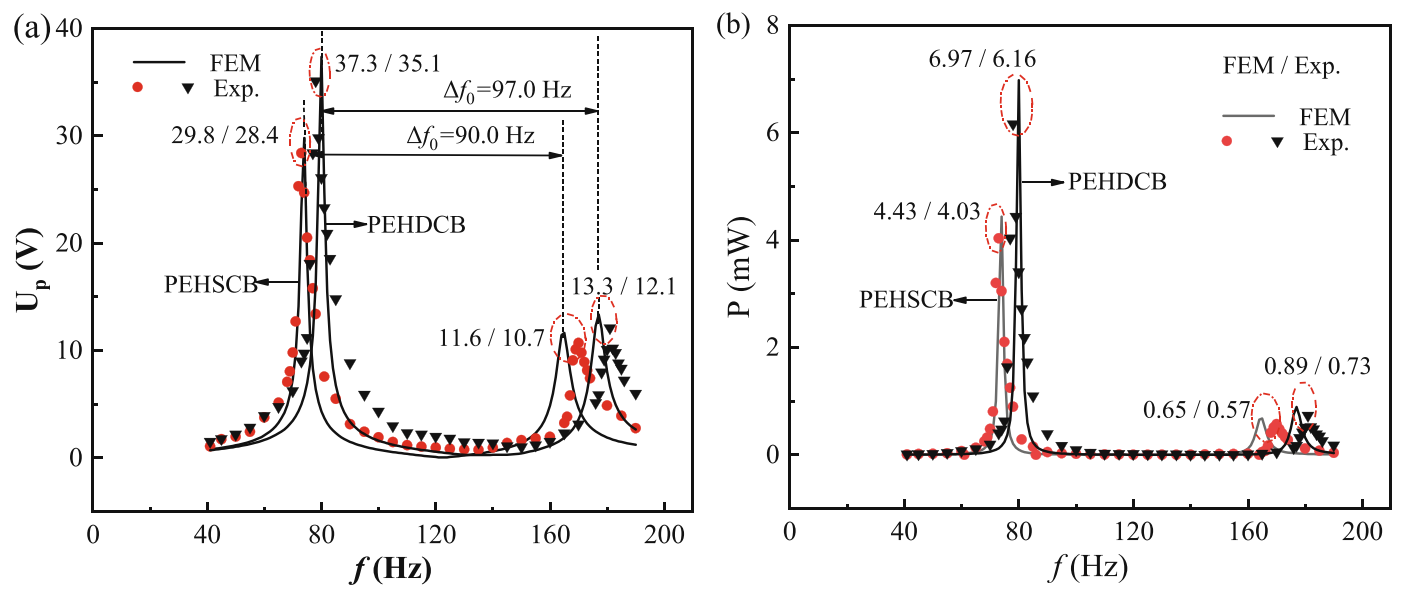

Figure 10. Effect of width splitting method on the $U_{\mathrm{p}}-f(\mathbf{a})$ and $\mathrm{P}-f(\mathbf{b})$ curves of PEHs undergoing coupled bending-torsion vibrations.

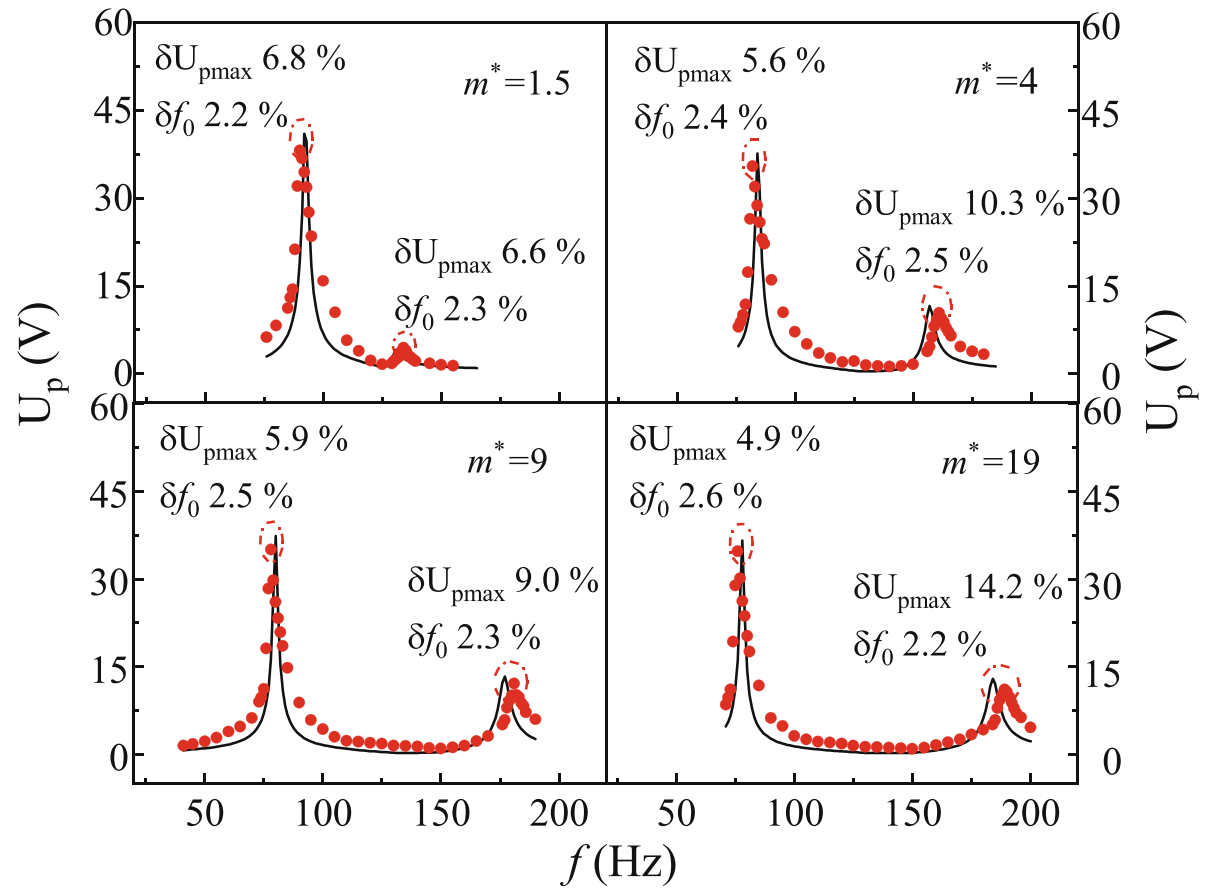

Figure 11. The $U_{p}-f$ curves under the different mass ratios $m^{*}$ for the PEHDCBs. 


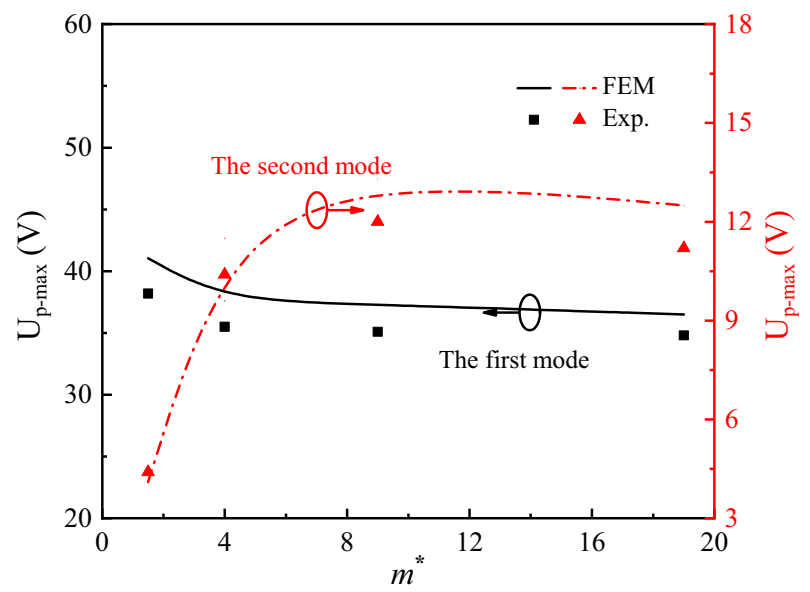

Figure 12. The $\mathrm{U}_{\mathrm{p}-\max }$ vs $m^{*}$ curves at the first and second modes for PEHDCB.

Received: 14 August 2021; Accepted: 22 December 2021

Published online: 12 January 2022

\section{References}

1. Vasiliev, M., Nur-E-Alam, M. \& Alameh, K. Recent developments in solar energy-harvesting technologies for building integration and distributed energy generation. Energy 12, 1080 (2019).

2. Rodriguez, R., Preindl, M., Cotton, J. S. \& Emadi, A. Review and trends of thermoelectric generator heat recovery in automotive applications. IEEE. T. Veh. Technol. 68, 5366 (2019).

3. Alsharif, M. H., Kim, S. \& Kuruoglu, N. How harvest more ambient energy from environmental vibration with a multiple-frequency excitation. Symmetry-Basel. 11, 865 (2019).

4. Wang, Q. et al. A synergetic hybrid mechanism of piezoelectric and triboelectric for galloping wind energy harvesting. Appl. Phys. Lett. 117, $043902(2020)$.

5. Zou, H. X. et al. Mechanical modulations for enhancing energy harvesting: Principles, methods and applications. Appl. Energy 255, 113871 (2019).

6. Alsaadi, N. \& Sheeraz, M. A. Design and optimization of bimorph energyharvester based on Taguchi and ANOVA approaches. Alex. Eng. J. 59, 117 (2020).

7. Tikani, R., Torfenezhad, L., Mousavi, M. \& Ziaei-Rad, S. Optimization of spiral-shaped piezoelectric energy harvester using Taguchi method. J. Vib. Control. 24, 4484 (2018).

8. Yu, J. \& Seshia, A. A. Power optimization by mass tuning for MEMS piezoelectric cantilever vibration energy harvesting. J. Microelectromech. S. 25, 108 (2016).

9. Beni, Y. T. Size-dependent electromechanical bending, buckling, and free vibration analysis of functionally graded piezoelectric nanobeams. J. Intel. Mat. Syst. Str. 27, 2199 (2016).

10. Abdelkefi, A., Barsallo, N., Tang, L., Yang, Y. \& Haji, M. R. Modeling, validation, and performance of low frequency piezoelectric energy harvesters. J. Intel. Mat. Syst. Str. 25, 1429 (2014).

11. Zhou, S., Yan, B. \& Inman, D. J. A novel nonlinear piezoelectric energy harvesting system based on linear-element coupling: Design, modeling and dynamic analysis. Sensors. 18, 1492 (2018).

12. Hosseini, R. \& Hamed, M. Improvements in energy harvesting capabilities by using different shapes of piezoelectric bimorphs. J. Micromech. Microeng. 25, 125008 (2015).

13. Goldschmidtboeing, F. \& Woias, P. Characterization of different beam shapes for piezoelectric energy harvesting. J. Micromech. Microeng. 18, 104013 (2008).

14. De, P. G., Soma, A. \& Fraccarollo, F. Piezoelectric energy harvesting for autonomous sensorse network on safety-improved railway vehicles. P. I. Mech. Eng. C-J. Mec. 226, 1177 (2011).

15. Avvari, V. P., Yang, Y. W. \& Kiong, S. C. Long-term fatigue behavior of a cantilever piezoelectric energy harvester. J. Intel. Mat. Syst. Str. 28, 1188-1210 (2016).

16. Kim, G. W. How harvest more ambient energy from environmental vibration with a multiple-frequency excitation. Int. J. Auto. Tech-Kor. 16, 645 (2015).

17. Abdelkefi, A., Najar, F., Nayfeh, A. H. \& Ayed, S. B. An energy harvester using piezoelectric cantilever beams undergoing coupled bending-torsion vibrations. Smart Mater. Struct. 20, 115007 (2011).

18. Jia, J. D. et al. An asymmetric bending-torsional piezoelectric energy harvester at low wind speed. Energy 198, 117287 (2020).

19. Dayou, J., Liew, W. Y. H., \& Chow, M. S. Increasing the bandwidth of the width-split piezoelectric energy harvester. Microelectronics J. 43, $2092(2012)$.

20. Im, J., Zhai, L., Dayou, J., Kim, J. W. \& Kim, J. The effects of width reduction on cantilever type piezoelectric energy harvesters. Proceedings. 9434, 94340w (2015).

21. Chow, M. S., Dayou, J. \& Liew, W. Increasing the output from piezoelectric energy harvester using width-split method with verification. Int. J. Precis. Eng. Man. 14, 2149 (2013).

22. Zou, H. X. et al. A magnetically coupled bistable piezoelectric harvester for underwater energy harvesting. Energy 217, 119429 (2021).

23. Youngsman, J. M., Luedeman, T., Morris, D. J., Anderson, M. J. \& Bahr, D. F. A model for an extensional mode resonator used as a frequency-adjustable vibration energy harvester. J. Sound. Vib. 329, 277 (2010).

24. Berlincourt, D., Krueger, H. A. \& Near, C. Technical Publication TP-226. Morgan Electro Ceramics. 187, 10 (2000).

25. Zhao, J. H. et al. Investigation of a d15 mode PZT-51 piezoelectric energy harvester with a series connection structure. Smart Mater. Struct. 21, 105006 (2012).

26. Fett, T., Munz, D. \& Thun, G. Tensile and bending strength of piezoelectric ceramics. Mater. Sci. Lett. 18, 1899 (1999). 
27. Duan, C. J. et al. Multi-factors analysis on the energy harvesting performance of PEH under multiple-frequency excitation. Smart Mater. Struct. 29, 085025 (2020).

28. Zhu, Y. K., Yu, Y. G., Li, L., Jiang, T. \& Zheng, X. J. Modeling and characterization of multilayered d15 mode piezoelectric energy harvesters in series and parallel connections. Smart Mater. Struct. 25, 075027 (2016).

29. Tso, C. F., Molitoris, D. \& Snow, S. Propped cantilever mesh convergence study using hexahedral elements. Packag. Transp. Storage Secur. Radioact. Mater. 23, 30 (2014).

30. Bagherifard, S., Ghelichi, R. \& Guagliano, M. Mesh sensitivity assessment of shot peening finite element simulation aimed at surface grain refinement. Surf. Coat. Tech. 243, 58 (2014).

31. Zhou, L. et al. A model for the energy harvesting performance of shear mode piezoelectric cantilever. Sens. Actuat. A-Phys. 179, 185 (2012).

32. Su, W. J. \& Shih, H. A. A U-shaped multi-modal bi-directional piezoelectric energy harvester. Appl. Phys. Lett. 113, 071905 (2018).

33. Xie, M., Aw, K., Edwards, B., Gao, W. \& Hu, P. How harvest more ambient energy from environmental vibration with a multiplefrequency excitation. J. Intel. Mat. Syst. Str. 25, 2228 (2014).

34. Wang, B. H., Lin, R., Liu, D. C., Xu, J. \& Feng, B. W. Investigation of the effect of humidity at both electrode on the performance of PEMFC using orthogonal test method. Int. J. Hydrogen Energy 44, 13737 (2019).

35. Sebald, G., Kuwano, H., Guyomar, D. \& Ducharne, B. Experimental Duffing oscillator for broadband piezoelectric energy harvesting. Smart Mater. Struct. 20, 102001 (2011)

36. Roundy, S., Wright, P. K. \& Rabaey, J. A study of low level vibrations as a power source for wireless sensor nodes. Comput. Commun. 26, 1131 (2003).

37. Abdelkefi, A., Nayfeh, A. H., Hajj, M. R. \& Najar, F. Energy harvesting from a multifrequency response of a tuned bending-torsion system. Smart Mater. Struct. 21, 07502 (2012).

38. Zhao, X., Zhu, W. D. \& Li, Y. H. Closed-Form Solutions of Bending-Torsion Coupled Forced Vibrations of a Piezoelectric Energy Harvester Under a Fluid Vortex. J. Vib. Acoust. 144, 021010 (2022).

39. Wang, D. A. \& Ko, H. H. Piezoelectric energy harvesting from flow-induced vibration. J. Micromech. Microeng. 20, 025019 (2010).

40. Lee, S., Youn, B. D. \& Jung, B. C. Robust segment-type energy harvester and its application to a wireless sensor. Smart Mater. Struct. 18, 095021 (2009).

41. Upadrashta, D. \& Yang, Y. Finite element modeling of nonlinear piezoelectric energy harvesters with magnetic interaction. Smart Mater. Struct. 24, 045042 (2015).

42. Fang, S. T., Fu, X. L. \& Liao, W. H. Modeling and experimental validation on the interference of mechanical plucking energy harvesting. Mech. Syst. Signal Pr. 134, 106317 (2019).

43. Upadrashta, D., Yang, Y. \& Tang, L. H. Material strength consideration in the design optimization of nonlinear energy harvester. J. Intell. Mater. Syst. Struct. 26, 1980 (2015).

\section{Acknowledgements}

This work was supported by NNSF of China (11832016, 51775471), Hunan innovative province construction special major landmark innovation demonstration project, Changsha Zhuzhou Xiangtan landmark engineering technology project (2019XK2303, 2020GK2014), Hefei general machinery research institute Co., LTD project (2021ZKKF043), and Postgraduate Scientific Research Innovation Project of Hunan Province (CX20200642).

\section{Author contributions}

X.Z. contributed to the conception of the study; J.S. performed the experiment; G.S. and X.Z. contributed significantly to analysis and manuscript preparation; X.L. and Q.B. performed the data analyses and wrote the manuscript; X.Z., J.S. and Q.B. helped perform the analysis with constructive discussions. All authors reviewed the manuscript.

\section{Competing interests}

The authors declare no competing interests.

\section{Additional information}

Correspondence and requests for materials should be addressed to X.Z.

Reprints and permissions information is available at www.nature.com/reprints.

Publisher's note Springer Nature remains neutral with regard to jurisdictional claims in published maps and institutional affiliations.

(i) Open Access This article is licensed under a Creative Commons Attribution 4.0 International License, which permits use, sharing, adaptation, distribution and reproduction in any medium or format, as long as you give appropriate credit to the original author(s) and the source, provide a link to the Creative Commons licence, and indicate if changes were made. The images or other third party material in this article are included in the article's Creative Commons licence, unless indicated otherwise in a credit line to the material. If material is not included in the article's Creative Commons licence and your intended use is not permitted by statutory regulation or exceeds the permitted use, you will need to obtain permission directly from the copyright holder. To view a copy of this licence, visit http://creativecommons.org/licenses/by/4.0/.

(c) The Author(s) 2022 